\title{
Do abril de 64 ao Al-2: a implantação inicial do regime militar no Brasil, segundo a diplomacia argentina
}

HELDER GORDIM DA SILVEIRA*

Resumo: O presente artigo analisa a forma pela qual a diplomacia argentina interpretou o golpe militar de 1964 no Brasil, procurando enfatizar como esse discurso, reproduzindo interpretações recorrentes, possivelmente atuou como uma ideologia da solução militar frente à crise política e institucional que crescia na região pelo menos desde a década de 1950.

Abstract: This paper analyses the way by wich argentine diplomacy interpreted 1964 military coup in Brazil, intending to underline how that discourse, as it reproduced recurent interpretations, possible acted as an ideology of military solution face of the political and institutional crises that was growing in the region since as early as the decade of 1950.

Palavras-chave: Regime Militar. Ideologia. Brasil-Argentina.

Key words: Military Regime. Ideology. Brazil-Argentina.

\section{Introdução}

$\mathrm{O}$ presente artigo insere-se em uma proposta mais ampla de pesquisa que busca examinar as formas de repercussão do golpe militar brasileiro na grande imprensa e na diplomacia argentinas, no período que se pode entender como de gestação e implantação do novo regime no Brasil, vivendo a Argentina os impasses do contexto de tutela militar dos governos radicais e do chamado Onganiato, do período1955-1971.

A referida proposta de pesquisa constitui seu objeto a partir do diálogo com o conjunto de concepções teóricas das Relações Internacionais que entende o Estado-nação como ator principal embora nunca exclusivo e em certas conjunturas relativamente debilitado - na constituição histórica dessas relações na modernidade.

* Professor da Graduação e do Programa de Pós-Graduação em História da Pontifícia Universidade Católica do Rio Grande do Sul.

Estudos Ibero-Americanos, PUCRS, v. XXXIV, n. 1, p. 121-141, junho 2008 
Nessa perspectiva, o conceito de inserção internacional referese, de forma ampla, aos variados modos de articulação ou desarticulação - constituídas principalmente pelas políticas externas dos Estados - entre duas ordens dinâmicas: a construção da hegemonia de um projeto nacional mais ou menos articulado, por um lado, e a efetivação de um certo padrão hegemônico de relações de poder nos cenários regional e global, por outro.

Tais planos, interno e externo, cuja inter-relação compõe a inserção internacional de um Estado-nação, são vistos, pois, como contextos historicamente estruturados ${ }^{1}$, isto é, com dinamismo marcado por assimetrias mais ou menos duradouras na posse de recursos materiais e simbólicos associadas a formas institucionais de exercício de poder na implantação de projetos nacionais mais ou menos articulados.

No quadro de tais contextos estruturados, constituem-se os objetos de análise aqui postos sob a noção geral de ideologia ${ }^{2} d a$ inserção internacional. Incluem-se na esfera de tais objetos as formas de mobilização do sentido as quais concorrem para racionalizarlegitimar, em uma conjuntura específica e em certos campos de produção discursiva, um dado processo de elaboração, crítica, execução ou reorientação de princípios e práticas concernentes ao que assim se põe como interesse nacional e como política externa a ele associada.

Neste quadro geral, destacam-se as construções discursivas que se põem como formas de interpretação de eventos ${ }^{3}$ relativos às políticas interna ou externa de outros Estados-Nação inseridos, por sua vez, em visões paradigmáticas de tais Estados-Nação bem como de respectivos cenários regional e global.

1 A noção de contexto socio-histórico estruturado apóia-se em THOMPSON, John. Ideologia e Cultura Moderna. Teoria Social Crítica na Era dos Meios de Comunicação de Massa. Petrópolis: Vozes, 1995, p. 71-90; inspira-se igualmente na noção de campo de interação social na linha de P. Bourdieu (cf. BOURDIEU, P. A Economia das Trocas Simbólicas, São Paulo: Perspectiva, 1992, p. 183-202).

2 O conceito de "ideologia" insere-se na linha proposta por John Thompson (op. cit., p. 71-104).

3 A noção de "evento" ou "acontecimento" como categoria essencial da história contemporânea, a partir da importância que nela assume a imprensa, inspira-se em NORA, Pierre O Retorno do Fato. In: LE GOFF, J. e NORA, P. História: Novos Problemas. Rio de Janeiro: F. Alves, 1979, p. 179-193. Uma discussão recente sobre a questão da curta duração em história contemporânea pode ser vista em GUARINELLO, Norberto L. História Científica, História Contemporânea e História Cotidiana. Revista Brasileira de História, São Paulo: ANPUH, vol. 24, n. 48, jul-dez 2004, p. 13-38. 
Propõe-se que tais construções discursivas podem atuar como ideologia da inserção internacional ao legitimarem, segundo estratégias diferenciadas de racionalização, as tendências postas nos diversos planos, internos e externos, daquela inserção e/ou sustentarem nas respectivas esferas discursivas uma posição crítica em relação a seus limites e possibilidades.

Nesse sentido, as formas de construção/interpretação de um evento em outro país, sempre associadas a certas representações paradigmáticas deste e do campo internacional, podem constituirse como racionalizações de uma ameaça a ser evitada, um exemplo a ser seguido ou uma manifestação de tendência posta como inevitável, para exemplificar. Tais formas gerais de interpretação ganham potência ideológica uma vez associadas à referida representação paradigmática do outro, sob noções de liderança e subordinação, em um plano vertical de representação das relações de poder, ou, em um plano horizontal, de aliança, cooperação e rivalidade atuais e potenciais.

\section{A Solução Revolucionária e seus sentidos no Brasil e na Argentina}

De forma geral, Brasil e Argentina representam-se mutuamente em tal plano horizontal como os países mais poderosos no cenário sul-americano e, eventualmente, como pólos de uma disputa pela supremacia estratégica em tal espaço. Nessa perspectiva, constroem-se, nos círculos diplomáticos, na grande imprensa e em outras esferas de produção discursiva, representações de identificações e contrastes em ambos os países relativas a eventos ou cursos de longo prazo de suas respectivas ordens socioeconômicas e políticas internas que ganham, assim, notável potencial ideológico no que tange à inserção internacional de ambos, aí incluídas as relações bilaterais situadas no contexto hemisférico frente à construção da hegemonia norte-americana, desde, pelo menos, o princípio do século XX. ${ }^{4}$

Na conjuntura da década de 1960, Brasil e Argentina atravessam os impasses e conflitos dramáticos condicionados pela crise

4 Panoramas gerais sobre a relação Brasil-Argentina podem ser vistos em SCENNA, Miguel. Argentina-Brasil Cuatro Siglos de RivalidadI. Buenos Aires: Ed. La Bastilla, 1976; BANDEIRA, Moniz. Conflito e Integração na América do Sul Brasil, Argentina e Estados Unidos da Tríplice Aliança ao Mercosul 1870-2003. Rio de Janeiro: Revan, 2003; FAUSTO, Boris e DEVOTO, Fernando. Brasil e Argentina Um Ensaio de História Comparada. São Paulo: Ed. 34, 2004. 
dos respectivos modelos de modernização socioeconômica das eras varguista e peronista como projetos nacionais, diante do cenário hemisférico e global da Guerra Fria. Cenário no qual a Revolução Cubana atuava como um extraordinário catalisador de tensões. ${ }^{5}$

Pretende-se aqui sustentar que a solução do abril de 1964 no Brasil repercutiu na diplomacia de Buenos Aires, particularmente nos informes produzidos pela embaixada no Brasil direcionados à chancelaria, de modo a concorrer para a (re)construção ali de uma ideologia de tal solução, justificando-a e explicando-lhe as origens e implicações no sentido de colocá-la em posição paradigmática para a Argentina e o subcontinente, considerando-se as identificações dos respectivos cenários internos frente a uma certa visão do contexto internacional.

Os elementos constituintes de uma tal ideologia, construída fundamentalmente na grande imprensa já ao longo da década anterior, associam-se às posições de poder dos grupos antivarguista e antiperonista no interior das Forças Armadas e em diversas esferas civis. Os condicionantes políticos do suicídio de Vargas e da deposição de Perón pela Revolução Libertadora de 1955 são emblemáticos das ações institucionais e extra-institucionais de tais grupos que, no entanto, por razões diversas, não logram obter imediatamente um re-ordenamento estável da ordem interna na direção de suas projeções. ${ }^{6}$

Importa aqui destacar, esquematicamente, os elementos de racionalização que conferiam sentido a tais ações, na forma como geralmente estes elementos se apresentavam na grande imprensa, no princípio da década de 1960.

5 Análises específicas da relação bilateral Brasil-Argentina no contexto podem ser vistas em CERVO, Amado Luiz. "Brasil e Argentina: Convergência de Desígnios e Diferença de Estilo (1945-1955)", disponível em http://scholar.google.com.br/ schhp?h/=pt-BR, acesso em 05/09/2007; CAVLAK, Iuri. "As Relações entre Brasil e Argentina no Início da Guerra Fria", História: Debates e Tendências, Passo Fundo, V. 6, n. 2, p. 83-109, $2^{\circ}$ sem 2006; VIZENTINI, Paulo G. F. "A Experiência Histórica do Brasil e da Argentina Contemporâneos: Autoritarismo e Desenvolvimento (19641985)", disponível em http://scholar.google.com.br/schhp?h/=pt-BR, acesso em 05/09/2007;

6 Análises gerais da história política recente da Argentina podem ser vistas em DONGHI, Tulio H. La Democracia de Massas. Buenos Aires: Paidós, 2000; DE RIZ, Liliana. La Politica en Suspenso 1966/1976, Buenos Aires: Paidós, 2000; POTASH, Robert. El Ejercito y la política en la Argentina 1962-1973, 2 vol, Buenos Aires: Ed. Sudamericana, 1994; ROMERO, Luis Alberto. Breve Historia Contemporánea de la Argentina. Buenos Aires: Fondo de Cultura Econômica de la Argentina, 2001; GOLDWERT, Marvin. Democracy, Militarism and Nationalism in Argentina, 1930-1966. Austin e Londres: University of Texas Press, 1972. 
De um lado, o dirigente representante da ordem a ser combatida - Goulart, no caso brasileiro, ou aquele que de algum modo reabre ou mantém os espaços da ordem deposta, os governos civis radicais e o peronismo, no caso argentino - tem sua imagem pública construída com base nas noções de "incompetência", "demagogia" e "populismo".

Incompetência fundamentalmente relativa à incapacidade para liderar o processo - sempre posto como técnico e necessário - de reformas na ordem socioeconômica no sentido de enfrentar as mazelas do subdesenvolvimento dentro dos padrões de ordem representados como naturais no interior de uma assim posta tradição democrática ocidental. Dessa incompetência deriva diretamente a noção de "caos" pela qual se qualifica geralmente a situação econômica do país sob os governos ditos populistas.

As noções de "demagogia" ou "populismo", por seu turno, associam-se a uma representatividade fundamentalmente ilegítima e viciada, a qual, seja por opção tática, seja por ingenuidade política, abre espaço para a penetração do totalitarismo comunista, precisamente posto como a antítese daquela tradição ocidental cuja eternalização fora posta no centro do conflito ideológico da Guerra Fria.

Dado que o sistema representativo assim viciado reproduz sua própria patologia política, tem-se a necessidade da Revolução Nacional, a qual, em um tal contexto de emergência e excepcionalidade, atuaria no sentido de depurar o sistema em essência e implantar as reformas técnicas e necessárias na ordem socioeconômica. Assim é condicionada a preservação dos fundamentos naturais dessa ordem e, no plano político, da democracia ou da constituição real, senão necessariamente da escrita, entendida em termos jurídicos liberais clássicos e em oposição aos totalitarismos alienígenas, no caso presente aquele representado pela ameaça comunista.

\section{A Revolução no Brasil vista pela diplomacia argentina}

Em fins de 1964, o Departamento América do Sul da Direção Geral de Política do Ministério das Relações Exteriores da Argentina produzia um extenso relatório no qual se expunham as linhas gerais da política de Buenos Aires no subcontinente ao longo do ano que findava. No que tocava especificamente às relações bilaterais com o Brasil, enunciava-se ali que "se han desarrollado este último año dentro de um ámbito de amplia cordialidad y compreensión". E particularmente, 
Con posterioridad a la instalación del nuevo gobierno revolucionário, se intensificaron los contactos, los que culminaron con la visita que el Canciller argentino Dr. Zavala Ortiz realizara al Brasil en los primeros días de agosto de este año lo que contribuyó a reafirmar esta política de acercamiento e identidad de princípios democráticos que presiden los actos de ambos gobiernos. ${ }^{7}$

Descontadas as formalidades próprias do discurso diplomático, bem como das visitas oficiais, aquele parece refletir a real aproximação do governo de Arturo Illia - o novo ensaio de governo civil radical sob tutela militar, no cenário de impasse político e institucional no qual vive a Argentina após a Revolução Libertadora antiperonista de 1955 - com o Brasil do novo regime, igualmente revolucionário implantado em abril.

Nesse sentido, faz-se o elogio dos documentos firmados quando da visita de Ortiz, os quais "conformaban actos concretos y recomendaciones tendientes a promover e intensificar el intercambio y cooperación en los aspectos comercial y cultural". Destacando-se a Declaração Conjunta firmada em agosto, aduz-se que esta

reafirma una perfecta solidaridad de objetivos e ideas existentes entre ambas naciones, destacando el echo de que están llamadas a participar en las soluciones de los grandes problemas que afligen a la humanidad reafirmándose el principio de que Brasil y Argentina, por razones políticas, demográficas y econômicas les compete una posición de vanguardia en la lucha para la erradicación de la pobreza, la ignorância y la injusticia. ${ }^{8}$

Novamente à parte os elementos meramente formais de retórica diplomática, parece que ambos os governos encontravam ocasião para retomar identificações recorrentes historicamente, no que toca a posições de liderança internacional - compartilhada ou competitiva - bem como de estratégias de superação das mazelas do subdesenvolvimento, agenda esta claramente dominante no pósguerra, presente, embora de maneiras diferentes, nos projetos nacionais concorrentes em ambos os países e mais recentemente formalizada no Encontro de Uruguaiana, entre os presidentes Frondizi e Quadros.

Neste cenário, ganha potência ideológica, entre a elite na esfera político-diplomática, sobretudo no interior do Estado, a interpre-

7 Ministerio de las Relaciones Exteriores y Culto. Dirección General de Política. Memo 1964/65. Cx. E71.

8 Ibidem. 
tação do movimento de abril de 1964 produzida pelo então embaixador argentino no Brasil, Carlos Alberto Fernández. Propõese que tal interpretação constitua uma manifestação de racionalizações recorrentes acerca do mesmo tema, nos campos jornalístico e político acima aludidas, privilegiada pelas posições de poder nas quais é construída e para as quais é destinada.

O embaixador embasa toda a sua racionalização acerca do movimento de abril, compondo a imagem de um país vivendo dias de paz e tranqüilidade políticas, em contraste contundente com a avaliação do regime caído e, pode-se claramente inferir, com a situação interna de seu próprio país, vítima, então, de uma revolução inacabada. Diz nessa direção Fernandez:

El año 1964 llegó a su término, com el país viviendo días de relativa tranquilidad y seguridad política. (...). En sus ocho meses iniciales, la revolución llegó a transformar en mucho la situación del país. Viendo el panorama actual, y el de enero passado, debemos admitir que existe uma fundamental diferencia. (...). El Brasil respira en cierta tranquilidad em su marcha hacia el futuro, en contraste con lo que se vislumbraba antes de la revolución, quando esse mismo futuro no era solamente un interrogante, sino por el contrario, una real amenaza. ${ }^{9}$

Aqui estão postos os elementos essenciais da racionalização: um estado de caos cuja superação impõe e legitima a saída revolucionária, cujo sentido essencial repousa na tarefa de depuração para a futura restauração de uma ordem natural, nos trilhos da tradição ocidental na qual se vê o país inserido desde os fundamentos da nacionalidade.

Vejamos o embaixador compondo o quadro do caos:

Diremos que el año [1964] comenzó muy mal para el país, con el reagravamiento del desorden existente, ya que podia facilmente apreciarse que el gobierno Goulart perdia el control de la situación política, a la vez que las contínuas crisis sociales asumían aspectos verdaderamente dramáticos. El despeñamento inflacionário hacia el que marchava Brasil, (...) la inexistencia de una controlada y técnica política económico-financiera, las inusitadas reivindicaciones sindicales que apremiaban al Poder Central eran (...) aspectos dominantes de esos dias. ${ }^{10}$

9 Carlos A. Fernandez a Miguel Angel Z. Ortiz. 20 de janeiro de 1965. Ministério de las Relaciones Exteriores y Culto, Fundo Arquivístico E, Cx 70, p. 1-2. Até nova referência, as citações referem-se a este documento.

10 Ibidem, p. 2. 
Nesse ambiente anárquico, que o discurso já põe em um passado tão recente quanto quase acabado por detrás da ruptura revolucionária de abril, situa-se a política assim vista como pseudoreformista dos últimos tempos do regime caído:

Partió allí, quizás como producto del atolondramiento a que fué llevado el Gobierno por todos estos problemas, uma 'carrera' hacia uma política reformista, que utilizó como bandera para la defensa de sus objetivos ideológicos, al tiempo que lanzaba sus críticas a las estructuras existentes que calificaban de arcaicas y que, en su sentir, acarreaban todos los males (...) que afligían a la nación. ${ }^{11}$

O reformismo goularista fica assim posto como "bandeira" falsa - para objetivos ditos "ideológicos" verdadeiros e amplamente favorecidos pelo caos. A designação ideológico, de resto, constitui sempre uma referência direta ao comunismo, nos quadros do discurso, também quanto a isso típico. Assim, fica reproduzida no discurso do embaixador uma das faces da figura política de Goulart então composta: um certo maquiavelismo posto em ações e discursos conscientes de sua condição de meio para atingir fins de natureza diversa em relação à sua aparência assim dissimuladora.

Entretanto, o que é também recorrente, cola-se a essa face da imagem de Goulart, uma outra, aparentemente em contradição com a primeira: a do líder político simplesmente incapaz de agir segundo o sentido dessa liderança, sendo assim vitimado, por essa própria incapacidade geradora de ingenuidade, pela ação de terceiros, mal postos em condição de aliados, estes sim agentes conscientes dos verdadeiros fins do suposto reformismo - os comunistas de variadas estirpes. Nesse sentido, diz o embaixador: "la incapacidad política del gobierno (...) y la desconfianza que sus líderes y sus métodos inspiraban (...), hacían la situación más grave a cada día". E ainda: "las reformas que no se concretaban y ni siquiera passaban la fase del estúdio preliminar, servían al solo objecto de aparentar la dinámica de um gobierno que no sabía concretar, en la realidad, sus objetivos de buena administración de la cosa pública". ${ }^{12}$

Entre esses extremos contraditórios do maquiavelismo e da incompetência mobilizava-se ainda para a composição múltipla da imagem de Goulart e seu (des)governo a tradição da idéia de demagogia. Nessa direção refere Fernandez: "puede decirse que

11 Ibidem, p. 2-3.

12 Ibidem, p. 3-4. 
la demagogia se instaló directamente em la Presidência de la República, y que a su nombre se gestaron impactos profundos para subvertir el orden público". ${ }^{13}$

Seja por maquiavelismo, por incompetência, ingenuidade ou demagogia a que se poderia agregar o qualificativo populista, o sentido real do processo político tal como este se apresentava no princípio de 1964 era um só:

los pasos del gobierno Goulart fueron (...) dirigidos hacia una evidente izquerdización que, si no revestía el carácter directamente comunista, favorecia ampliamente la acción de los líderes de tal ideología, interesados en aumentar el caos y favorecer el desorden como elementos propícios a la implantación posterior de su régimen. ${ }^{14}$

Esse sentido último das tendências do cenário político retratado, criava, nas palavras do embaixador, "un verdadero ambiente revolucionário". Põe-se aqui o aparente duplo sentido da idéia de Revolução, mobilizada na construção dos fundamentos simbólicos legitimadores/mobilizadores da solução de abril e suas congêneres no Cone Sul, conforme se tenta inferir aqui nos indícios apontados pelo discurso do diplomata argentino. Tal duplo sentido é a base da racionalização recorrente segundo a qual a Revolução de abril, "en que se reencontró el país", emerge de uma ContraRevolução. Vale dizer, a Revolução na qual o país é reencontrado surge de um movimento - nacional e consciente - contrário à outra Revolução, cuja possível vitória representaria sua perda. Diz a respeito o embaixador:

la estructura que podríamos llamar contra-revolucionaria, opuesta totalmente a los planes del Gobierno, hacía mucho tiempo que preparava su acción. Aunque siempre listas para reaccionar ante el menor intento de un golpe oficial, por parte de los ideólogos que estaban encaramados en el poder, estas fuerzas nunca se sintieron lo suficientemente aptas para reacccionar abiertamiente, ya sea por falta de confiaza em su poderío, o quizás (...) por el temor de dar un paso en falso que pudieraprivarles del poder de reacción en masa. ${ }^{15}$

Entretanto, este movimento nacional reativo em sua essência iria encontrar fundamentos para transitar da reação à ação, numa transformação qualitativa essencial. Nas palavras do embaixador, criaram-se circunstâncias para "operarse la transformación de la 
contra-revolución, hacia la real revolución que surgió el 31 de marzo". Vale dizer, o 31 de março, no interior da racionalização assim posta, supera a condição de mera reação na qual se origina para constituir-se em um movimento de ruptura radical, constituinte de uma nova ordem, embora restauradora e depuradora em seu significado político essencial, em uma operacionalização de noções fundantes da tradição liberal. Daí a legitimidade para que se rompesse, para restaurá-la em novos termos, "la firme convicción de respeto hacia el primado de legalidad, que trasciende de todos los sectores de la vida nacional brasileña".

Tal passagem da reação à ação revolucionária deu-se "solamente al (...) herirse profundamente las herarquías militares, ya sea por acción deliberada o ineptud oficial", quando "las mentes dirigentes del movimiento se decidieron a pasar de una etapa a la outra, la definitiva, que desembocó en la directa salida revolucionaria". ${ }^{16}$

Em que pese haver sido deflagrada a partir de interesses mais diretamente ligados à esfera hierárquica das Forças Armadas - o embaixador confere importância crucial, nesse sentido, para os episódios do Clube Naval e do Automóvel Clube -, a Revolução sustentava-se por seu caráter inequivocamente nacional e por seus propósitos essenciais, em última análise francamente civilistas. Assim:

la revolución antigoularista fué realizada sin disparar prácticamente um solo tiro, con las organizaciones sindicales y estudantiles disgregadas por falta de reales liderazgos (...), mientras que el esquema militar revolucionário recibía inúmeras adhesiones en todo el território nacional. De esta forma fué relativamente fácil concretar la toma del Poder y el reestablecimiento del orden en todo el país, com maniobras de tipo militar que deben ser consideradas de mero valor psicológico. ${ }^{17}$

Assim, "ante la vocación civilista y democrática de los militares, la acción organizada de grupos políticos intentaron desvanecer la verdadera finalidad del movimiento". Entretanto, "prevaleció la tesis de los que defendían la existência real del movimiento, como un principio revolucionário".

Veja-se nessa direção a análise do embaixador argentino sobre o marco jurídico fundador da revolução nacional brasileira:

16 Ibidem, p. 5.

17 Ibidem, p. 6. 
con el Acto Institucional, la Junta Militar se reveló ante el consenso popular. A través del mismo se armaron los quadros en los quales se afirmó la revolución, y por su intermedio se mantuvo y revigorizó al Congreso Nacional. Ello demonstró, una vez más, el sentido civilista de los militares brasileños.

Ficava assim demarcado com bases firmes no terreno da reordenação jurídica o limite que apartava o movimento de 31 de março da condição de mera ditadura de tipo militar. Refere ainda Fernandez a seu Ministro de Exteriores:

Contando con todas las posibilidades de elegir el camino fácil y seguro de armar uma dictadura, las autoridades prefirieron buscar el apoyo de juristas y políticos de formación y relevantes condiciones democráticas para encontrar la fórmula 'intermedia' que les posibilitase la promulgación de un elemento legal y revolucionário que permitiese al Poder Ejecutivo contar con algunos dispositivos de fuerza para facilitar sus primeros pasos políticos. ${ }^{18}$

É assim que não constitui nenhum tipo de contradição no interior do quadro discursivo a assertiva, de notável robustez ideológica na qual se articulam de modo coerente e ancorado na tradição doutrinária de corte liberal, menções de punição, afastamento, revolução e democracia, segundo a qual "es con la elección indirecta del nuevo Presidente de la República, y el alejamiento de inumerables políticos y militares que integraron las primeras listas de punidos por la revolución, que se inicia el processo revolucionário de redemocratización brasileña".

A eleição de Castelo Branco, posta como "encabezada por el grupo de Gobernadores que se había integrado en el movimiento" e contando con "el apoyo decidido de los militares", é vista pelo embaixador como garantia segura de preservação do elo civilmilitar de raiz democrática posto na base do movimento de 31 de março. É assim que afirmaria o diplomata a Buenos Aires:

desde um comienzo, fué evidente el deseo del Presidente Castelo Branco de caracterizar su Gobierno en um amplio sentido civilista. Dejando de lado su posición militar, de la que se alejó oficialmente, aún antes de iniciar su tarea gubernativa, procuro dejar bién aclarado que no recorreria el ya conocido camino del caudillismo, camino al cual encontraba abiertas muchas brechas políticas. ${ }^{19}$

A figura pessoal e política bem como os fatos assim constituídos novamente reforçavam a diferença essencial do movimento 
em relação aos caminhos do caudilhismo, de significação potente, para muitos sentidos, no cenário latino-americano.

A integridade do painel discursivo deveria, entretanto, enfrentar a questão posta, nas palavras do embaixador, pela "lucha tenaz y sostenida de los grupos que pretendían instaurar rápidamente el 'imperio de la revolución'". ${ }^{20}$ Tal integridade será perfeitamente sustentada pela estratégia de posicionar as ações da chamada linha dura revolucionária no interior das noções complementares de excesso e exceção, de todo modo controlados pela ação política, punitiva ou negociadora, do governo revolucionário de Castelo Branco. Refere o embaixador a respeito desta ação do governo Castelo em relação à linha dura:

la maniobra táctica fué ejecutada en secuencias limitadas y por etapas, y con ello se logró encuadrar en el processo gubernativo a los principales jefes militares del movimiento revolucionário. Los que no quisieron o no supieron adaptarse a esa tónica impuesta por Castelo Branco, debieron conformarse con el alejamiento de sus cargos o aceptar traslados (...) que les desvincularon prontamente del panorama que tenían ante si. ${ }^{21}$

Assim, o governo revolucionário "comenzó la tarea de poner en su lugar los excesos cometidos por aquellos militares que, validos de los poderes extra-legales, habíanse apartado de la verdadera justicia". Todavia, essas diferenças quanto a ritmos e métodos no interior dos quadros revolucionários jamais tocavam uma diferença essencial de propósitos finais ou que diziam da própria natureza da revolução. Assim, poderia o embaixador considerar de forma sempre coerente que "la 'línea dura' revolucionaria no perdió su cohesión, ni mucho menos desapareció - como muchos creyeron". E complementava: "ante [varias] acciones que evidenciaban el grado de decisión y unidad de los círculos afactos a tal línea política, el Gobierno no exhibió ni demostró su pesar, por el contrario, en ciertas medidas apoyó decididamente las 'sugestiones' que desafiaban abiertamente todos los princípios legales vigentes. ${ }^{22}$

Longe de representar debilidade do governo revolucionário, tal fato compunha uma advertência política:

esto es ampliamente demostrativo de que no existe un divorcio político-militar entre el gobierno revolucionário y la llamada 'línea

20 Ibidem, p. 9.

21 Ibidem, p. 9-10.

22 Ibidem, p. 10. 
dura', tal como pretenden ver algunos espíritus interesados enpasar rapidamente a la legalidad político-electoral para lucrar con la débil madurez que hasta allí pueda alcanzar la revolución y sus métodos depurativos y esclarecedores. ${ }^{23}$

Compõem-se assim a coesão ideológica do quadro discursivo com o apelo à natureza depuradora da revolução nacional sobreposta à legalidade formal, sempre passível de instrumentalização demagógica. Nessa mesma estratégia essencial o discurso enquadra igualmente os excessos policiais do novo regime que vinham a público:

esos aspectos 'dudosos' de la actividad oficialista, tienden en general hacia una acción intimidatoria del tipo físico-cultural, que hasta hoy, han sido anulados em su gran parte por la acción del Presidente de la República, apoyado por altos Jefes Militares que secundan abiertamente su tarea. Esas excepciones no reflejan ni comprometen en líneas generales, el ambiente em que se desenvuelven las actividades políticas, ambiente diríamos, diametralmente opuesto al que existia a fines de 1963 y a comienzos de $1964 .^{24}$

Assim se enfeixa a representação dada ao Ministério de Exteriores argentino, da revolução de 31 de março, consolidada como projeto nacional brasileiro. Nas palavras do embaixador:

si hacemos una exploración da la verdadera opinión pública encuanto a la situación, encontraremos que la gran mayoría del pueblo siente y aprueba que el gobierno Castelo Branco viene actuando com elevada decencia y honestidad para encaminar al país hacia la gran solución nacional, no solamente en el sentido político, sino también en el social y cultural, y en lo econômico. ${ }^{25}$

Ocioso recordar o paralelo das situações nacionais - notadamente aquela entre goularismo e peronismo - e as condições do contexto regional e hemisférico, como o não-dito do discurso, para perceber a potencialidade ideológica do panorama sóciopolítico brasileiro assim composto pelo discurso diplomático argentino.

Sempre acompanhando de perto a evolução política da Revolução brasileira e identificando sempre duas tendências no interior do movimento - aquela liderada pelo presidente, supostamente moderada, e a chamada linha dura -, a embaixada argentina, através de Carlos Alberto Fernandez, centra as análises 
políticas do segundo ano da Revolução, por um lado, no processo de cassações e intervenções nos estados, com destaque para o caso de Goiás, e para as ações políticas de potenciais candidatos às eleições presidenciais, então previstas para 1966, como Ademar de Barros, Carlos Lacerda e Juscelino Kubitschek, e, por outro, nas eleições para governador em onze estados da federação, marcadas para 3 de outubro, vistas como um teste eleitoral para o movimento de 1964, tendo em vista os seus propósitos essenciais e, mais imediatamente, o que se previa então para 1966.

Conhecidos os resultados do pleito, o embaixador assevera:

a pesar de toda la fuerza y énfasis puesta de manifiesto por el Gobierno revolucionário para señalarante la opinión pública que la revolución no estaba siendo juzgada, la campaña electoral evidenció lo contrario de esta afirmación. ${ }^{26}$

E concluía: "los candidatos de las posiciones oposicionistas (...) se identificaron decididamente con la bandera anti-revolucionaria o por lo menos con las aspiraciones revanchistas de algunos sectores políticos alejados de las áreas del poder".

Os resultados das eleições de 3 de outubro, principalmente em estados da importância da Guanabara, de Minas Gerais e Goiás, selavam a sorte das eleições diretas de 1966, pois, na visão do embaixador, mesmo antes de tais resultados negativos,

los observadores militares del gobierno revolucionário habían recogido suficiente información como para configurar un cuadro definitivo respecto de las possibilidades electorales que existen para la confrontación convocada para la sucesión presidencial (...). Ello les llevó a la conclusión de que el país no cuenta con suficientes garantias ni possibilidades que le permitan aguantar el impacto de unas elecciones presidenciales, dentro de los términos democráticos normales.

A crise, assim posta, conduzia o processo revolucionário brasileiro a uma encruzilhada. Nas palavras do embaixador argentino:

esta crisis (...) tiene que optar (sic) por buscar una solución sin violências y que le permita, a la Revolución, su reencuentro para el tramo político final, o será canalizada hacia drásticas medidas que pueden llevar a la concreción de una nueva revolución dentro de los planteos y princípios de la actual.

26 Ofício de Carlos Alberto Fernandez a Miguel Angel Zavala Ortiz, 14 de outubro de 1965. Ministério de las Relaciones Exteriores y Culto. Memos 1964/1965. Fundo Arquivísitico E, Cx 71. Até nova referência, as citações referem-se a este documento. 


\section{E prossegue:}

de sucederse la primera de estas soluciones, el país seguirá acortando distancias hacia la salida deseada, aunque apartándose cada vez más de los moldes democráticos que quiere imprimirle, de serlo la segunda de ellas, romperá definitivamente con su máscara legalista con la cual se cubre desde el início de su gestión, para entrar en el camino de las realizaciones políticas netamente revolucionárias, que no han de hesitar ante inconvenientes o planteos de tipo político partidario, llevando adelante los esquemas y realizaciones que determinó e impulsó el movimiento del 64.

Para além do acerto na projeção de um futuro próximo nos rumos políticos do movimento de 1964, é de se acentuar na análise da embaixada Argentina os elementos essenciais da racionalização acerca daquele movimento, que vimos aqui apontando em sua potencialidade ideológica.

Em primeiro lugar, a noção de Revolução incorporada no discurso e que lhe serve sempre como pano de fundo na construção do sentido para o 1964: uma ação-processo político detentor do poder constituinte e instituinte originário e que assim se autolegitima, no interior de uma apropriação da tradição ocidental, conveniente para o contexto interno e externo, no sentido de estabelecer uma diferença de fundo em relação a opções autoritárias, presentes e ameaçadoras, com desígnios completamente estranhos àquela tradição, conforme discutido acima.

Desse modo, se põe, na visão aqui examinada, a relação - tensa - entre a Revolução, ocidental/democrática, como processo que se aprofunda necessariamente em seus propósitos essenciais ("nueva revolución dentro de los planteos e principios de la actual..."), e a constituição formal, ao menos parcialmente vigente, com suas decorrências políticas e jurídicas - de resto viciadas pela demagogia, a incompetência, a corrupção ou mesmo a ingenuidade política do regime e das lideranças populistas - a ser preservada, ou não, no decorrer, posto como inexorável, daquele processo.

Essencial igualmente na tessitura do discurso é a identificação tácita daqueles propósitos revolucionários essenciais com os interesses históricos, ou de fundo, do País, não necessariamente com maiorias expressas em processos eleitorais ainda viciados ("el país no cuenta con suficientes garantias"; "el país seguirá acortando distancias", etc.). É assim que a Revolução enfrentaria a referida alternativa de preservar ou não os "moldes democráticos", os "términos democraticos normales" ou mesmo 
uma "máscara legalista", na consecução de suas metas fundamentais. Nessa perspectiva, põe-se precisamente o conflito interno - a ser de todo modo superado - entre o presidente Castelo Branco, na liderança dos ditos moderados, e a chamada linha duracom a concordância entre as correntes revolucionárias quanto aos propósitos finais do processo sempre marcando os rumos da Revolução, na visão que Carlos Alberto Fernandez constrói para sua chancelaria.

Nessa direção, vejamos o embaixador construindo o sentido revolucionário para o decreto do Ato Institucional número 2 (AI-2).

\section{O Al-2 como final do Primeiro Ato}

Junto à tradução de inteiro teor do AI-2 e do Ato Complementar número 1, a embaixada argentina envia suas primeiras impressões a Buenos Aires.

la primera reacción general ante el conocimiento del contenido de este nuevo Acto Institucional, ha sido de franco asombro, no tanto por inesperado, sino por la magnitud de las medidas que el mismo encierra. Es tan amplio el poder que otorga, que solo podría justificarse ante problemas de una seriedad fundamental, un peligro inminente, o un deseo de gobernar con poderes extraordinários. Nadie consideró en momento alguno que el país estuviese pasando por un peligro, ya sea de desorden, rebelión, subversión, etc. que justifique las medidas ordenadas. ${ }^{27}$

Embora já houvesse feito projeções muito precisas, como se viu, acerca de um aprofundamento do processo revolucionário, o embaixador parece compartilhar, inicialmente, do assombro geral causado pela amplitude de poder que encerrava o AI-2. Entretanto, sempre na coerência do quadro que vem traçando para sua chancelaria - cuja incorporação das noções que subjazem ao próprio discurso da Revolução, bem como sua recorrência discursiva, podem emprestar-lhe efeitos ideológicos - Fernandez não vê um caráter meramente reativo na medida revolucionária. Ao contrário, tal como fizera ao interpretar o AI-1, trata de identificar o princípio ativo, de institucionalização, ou aprofundamento real, de um processo sempre revolucionário, a embasar a edição do novo Ato. Refere nesse sentido:

27 Ofício de Carlos Alberto Fernandez a Miguel Angel Zavala Ortiz, 29 de outubro de 1965. Ibidem. Até nova referência, as citações referem-se a este documento. 
pareceria que se ha querido aprovechar la oportunidad para incorporar todos los proyectos que el Poder Ejecutivo aspiraba presentar con el correr del tiempo, y que de esta manera se han visto convertidos en realidad sin necesidad de caer en las difíciles deliberaciones del Congreso Nacional.

Todavia, tal intenção é apenas parte do projeto revolucionário, pois para tanto, "sólo bastaba, por intermédio de un acto como el presente, convertirlos en leyes, sin llegar por ello a modificar los tres poderes, disolver los partidos políticos, modificar la Corte Suprema, reglamentar la libertad de los inhabilitados políticos, etc.". Assim, pode concluir o embaixador não se tratar o AI-2 de mera reação conjuntural do governo revolucionário face a possíveis dificuldades circunstanciais:

Ya lanzado el Poder Ejecutivo a la necesidad de um Acto Institucional, se le incorporaron a este todas aquellas medidas que posteriormente podrían llegar a hacer necesario un nuevo instrumento para efectivarlas, evitando para el futuro posibles discusiones o actitudes opositoras a los mismos, pués, insistimos, nada hacía previsible medidas tan drásticas en el momento actual.

Assim estabelecida a perspectiva de futuro e de aprofundamento do projeto revolucionário, pode Fernandez praticamente colar a seu discurso as justificativas oficiais brasileiras:

los motivos aducidos fueron los seguientes: garantir la conquista de sus objetivos, apartar definitivamente todo movimiento de carácter revanchista, reaccionario e contrarevolucionario, procurar consolidar el orden político, financiero y econômico, imposibilitar la continuidad de la corrupción (...), al mismo tiempo que reiteraba la vigência de los motivos que hicieron necesaria la Revolución del 1 de abril de 1964.

No que toca às reações nacionais ao Ato, trata o embaixador de conferir destaque ao que importa e do modo como importa:

en forma general los legisladores presentes en Brasília se abstuvieron de hacer cualquier tipo de comentários al respecto (...). En los círculos militares por el contrario, se hizo ver un franco alivio, una verdadera alegria en ver nuevamente a la Revolución con toda su primitiva fuerza y poder. El Acto Institucional sin duda ha conseguido unir nuevamente las filas militares en torno al Presidente de la República. (...). Los Comandantes de los cuatro Ejércitos han hecho llegar al Presidente sus felicitaciones.

Note-se o bem vindo destaque à unidade das correntes revolucionária no interior do aprofundamento do processo de implan- 
tação do projeto que fundamenta essa perspectiva do 1964. É assim que Fernandez pode enfeixar sua análise inicial do AI-2 em um tom de franco otimismo, sempre incorporando o discurso oficial brasileiro e constituindo, talvez, um canal de reforço de posições análogas no interior do Estado argentino, conforme vimos discutindo. Assim:

podemos decir que el país se ha mantenido en calma, las Fuerzas Armadas han dado su voto de aprobación a la medida, que por outra parte pareceria haberlas unido más estrechamente, no há existido hasta el momento ninguna reacción violenta o negativa por parte de los partidos políticos, y el Gobierno (...) insiste em destacar que, si bien se han cercenado algunas libertades, ello se há hecho en bien de la futura democracia que habrá de regir los destinos del país a partir de 1967.

Sempre no interior desses pilares básicos do discurso, em suas relações, por vezes tensas, mas nunca contraditórias - Revolução, Democracia Ocidental, Destino Histórico Nacional, Constituição Formal, Legalidade -, Carlos Alberto Fernandez trataria de refinar e aprofundar a análise que apresenta a sua chancelaria acerca do significado, da forma e das implicações políticas do AI-2.

Nesse sentido, o embaixador muito rapidamente retoma a dicotomia castelistas versus linha dura no interior de sua visão das forças revolucionárias, em que pese haver saudado de forma enfática, como se viu, a unidade dessas forças provocada pelo decreto do AI-2 e não obstante insistir sempre tratar-se de divisão quanto à forma, jamais quanto ao fundo do processo revolucionário.

Precisamente nesse plano formal, Fernandez irá identificar no AI-2 uma influência decisiva da chamada linha dura sobre a presidência e o grupo que esta mais diretamente representaria. Nesse sentido, chega a referir "que el mariscal Castelo Branco se vió, en cierta forma, obligado a éllo, por las presiones que soportaba, y que cada dia eran más poderosas". E: "inclusive podemos llegar a suponer que no há de estar en un todo de acuerdo con la forma abrupta que se debió adoptar" ${ }^{28}$

Em que pese tratar-se de divergência quanto à forma e não quanto ao conteúdo da Revolução, o aspecto formal não deixava, na ótica do embaixador, de ter relevância específica, a justificar, de certo modo, a posição moderada presidencial:

28 Ofício Carlos Alberto Fernandez a Miguel Angel Zavala Ortiz, 5 de novembro de 1965. Ibidem. 
siempre hemos visto al Presidente de la República abocarse con indiscutido entusiasmo al mantenimiento de las Instituciones que hacen a la vida democrática del país, procurando presentar al exterior, una imágen de la Revolución lo más cercana posible a la legalidad constitucional. El acto Institucional N 2 evidentemente há hechado por tierra tales deseos, y su repercusión en el exterior há sido francamente desfavorable dando con ello razón a lo que suponemos eran los deseos de evitarlo del Mariscal Castelo Branco.

É assim posta no plano das repercussões internacionais a grande relevância para o cuidado que deveria manter a Revolução quanto às relações, de difícil encaminhamento, entre seus propósitos de fundo e a preservação do aparato constitucional/legal vigente. Aqui, precisamente, coloca o embaixador a importância real das diferenças formais entre castelistas e linha dura na condução do processo revolucionário, não sem exibir uma clara simpatia em relação àqueles, ao mesmo tempo que acentua por vezes o realismo destes.

Tal problema essencial de forma na condução dos rumos da Revolução parece constituir o pano de fundo da análise mais acabada que o embaixador argentino constrói com relação ao AI-2.

Comparando, nessa análise, o Ato de 27 de outubro de 1965, com o anterior, de 9 de abril de 1964, Fernandez, reforça sua primeira impressão de que "resulta evidente la mayor amplitud y profundidad de las medidas y objectivos" 29 do AI-2. Nesse sentido refere o diplomata:

a pesar de lo riguroso de lo estabelecido en los artículos 7 y 10 del Acto Institucional N 1, el Gobierno se mantenía en relación de dependencia formal con el sistema jurídico y legal existente $\mathrm{y}, \mathrm{m}$ á $\mathrm{s}$ aún, en la necesidad de entenderse con los otros poderes o de 'manejarlos' de manera indirecta. Aúnque desarmonizados, los três elementos clásicos de Poder permanecían independentes.

Aí posta uma vez mais a questão da implantação do projeto revolucionário diante da necessidade de preservação da ordem político-jurídica pré-existente. Inobstante justificar e apresentar simpatia pela postura moderada dos castelistas a respeito do problema, como se viu, o embaixador comporá análise no sentido de sustentar o AI-2 como decorrência natural da lógica política revolucionária, acima das eventuais divisões no seio das forças construtoras da Revolução.

29 Ofício Carlos Alberto Fernandez a Miguel Angel Zavala Ortiz, 10 de novembro de 1965. Ibidem. As citações que seguem referem-se a este documento. 
Nesse sentido, no que toca especificamente às relações da Revolução, assentada fundamentalmente no Executivo, com o Poder Judiciário, cuja estrutura funcional e legal básica o AI-1 preservara, assevera Fernandez:

ante la evidencia de las leyes vigentes, los jueces de las diferentes instancias eran obligados a contrariar los deseos de los sectores revolucionários más exaltados, independentemente de sus vocaciones y creencias personales, así como de sus puntos de vista con relación a cada una de las situaciones presentadas por el accionar del movimiento de março de 1964.

A preservação do aparato jurídico formal apresentava-se assim como entrave legal para a consecução política dos objetivos revolucionários, sempre na lógica argumentativa rigorosa do embaixador, a emprestar extraordinária potência ideológica à recorrência dos conceitos chave do discurso.

O impasse chegava mesmo ao Superior Tribunal Militar, no qual, segundo o embaixador, verificava-se "la repetida concesión de 'Habeas Corpus' a los acusados de subversión". De outra parte:

las repetidas tentativas de reforma de los textos judiciales, encontraban los obstáculos naturales de la letra constitucional, ya que, en relación directa a la Corte Suprema de Justicia, le atribuía prerrogativas inalienables que le aseguraban la iniciativa en cualquier tentativa de modificación del estado existente al respecto.

Novamente a representação do texto constitucional como forma ("letra") frente aos propósitos instituintes do processo revolucionário em marcha.

Quanto às relações com o Legislativo Federal, igualmente a Revolução aparece obstaculizada pela preservação das formas democráticas do Estado, não obstante os poderes especiais do Executivo e o processo de depuração pelas cassações de mandatos. Nessa direção refere Fernadez:

a pesar de esos poderes especiales en el Poder Legislativo, se mantenía latente la posibilidad de rechasar los envios del Ejecutivo. Este último, único poder del momento en el cual se encarnaba la voluntad revolucionaria, se encontraba siempre obligado a negociar, sistema que le conducía inevitablemente a um desgaste permanente de su autoridad que aumentó con el transcurrir del tiempo.

É assim que a edição do AI-2 pode ser posta como a solução institucional possível para as tensões, de outro modo insolúveis, que naturalmente se teriam estabelecido entre os propósitos 
revolucionários, democráticos quanto aos fins políticos últimos, e a preservação parcial do ordenamento constitucional - formal - então vigente. Nessa linha de argumento, conclui Fernandez:

el 27 de octubre último, el Comando Revolucionário, especialmente entrosado em las Fuerzas Armadas, se decidió a confeccionar um nuevo instrumento que les alejara de los peligros que la inercia política, por um lado, y las tentativas de reaparición de certos grupos políticos bien definidos y opositores, pretendían crearle hasta la fecha fijada para dar la solución democrática prometida oportunamente al pueblo brasileño.

Portanto,"el Acto Institucional N 2 se tornó posible por la confluencia, hacia un mismo objectivo táctico, de fuerzas actuantes en esferas revolucionarias, algunas de ellas indecisas en cuanto a la aplicación de procedimientos drásticos".

A percepção da Embaixada argentina assim racionalizada acerca da implantação inicial do regime civil-militar brasileiro de 1964 certamente incorporava interpretações recorrentes do mesmo processo, no Brasil e na Argentina, conforme discutimos. O que se buscou aqui acentuar é que precisamente essa recorrência, expressa e difundida nos mais altos escalões do Ministério de Relações Exteriores e do Executivo no governo Arturo Illia, através da palavra do embaixador em um país-chave para a política externa e interna de Buenos Aires, possa ter sido a base da potência ideológica daquela racionalização, na direção de conferir-construir sentido à solução autoritária em ambos os países, no contexto da Guerra Fria, dentro do que aqui se denominou ideologia da inserção internacional.

Talvez nesse sentido deva-se enxergar a visão conservadora segundo a qual o golpe de 1966 na Argentina e o regime do Onganiato, que se punha no horizonte imediato do governo Illia, tenham falhado em seus propósitos revolucionários precisamente por não terem levado às últimas conseqüências um necessário processo de "brasileirização" do movimento. 